\title{
Nonlinear Fuzzy Model-base Technique to Compensate Highly Nonlinear Continuum Robot Manipulator
}

\author{
Farzin Piltan \\ Senior Researcher at Research and Development Unit, Sanatkadehe Sabze Pasargad Company, (S.S.P. Co), Shiraz, Iran \\ E-mail: Piltan_f@iranssp.com
}

\author{
Mehdi Eram \\ Research and Development Unit, Sanatkadehe Sabze Pasargad Company, (S.S.P. Co), Shiraz, Iran \\ E-mail: SSP.ROBOTIC@yahoo.com
}

Mohammad Taghavi

Research and Development Unit, Sanatkadehe Sabze Pasargad Company, (S.S.P. Co), Shiraz, Iran E-mail: SSP.ROBOTIC@yahoo.com

Omid Reza Sadrnia

Research and Development Unit, Sanatkadehe Sabze Pasargad Company, (S.S.P. Co), Shiraz, Iran E-mail: SSP.ROBOTIC@yahoo.com

Mahdi Jafari

Research and Development Unit, Sanatkadehe Sabze Pasargad Company, (S.S.P. Co), Shiraz, Iran E-mail:SSP.ROBOTIC@yahoo.com

\begin{abstract}
Refer to this research, a gradient descent optimization methodology for position fuzzy - model based computed torque controller (GDFCTC) is proposed for highly nonlinear continuum robot manipulator. The main problem of the pure computed torque controller (CTC) was equivalent problem in uncertain systems. The simulation results exhibit that the CTC works well in certain system. To eliminate the continuum robot manipulator system's dynamic; Mamdani fuzzy inference system is design and applied to CTC. This methodology is based on applied fuzzy logic in equivalent nonlinear dynamic part to estimate unknown parameters. This relatively controller is more plausible to implement in an actual real-time when compared to other techniques of nonlinear controller methodology of continuum arms. Based on the gradient descent optimization method, the PD-gain updating factor has been developed in certain and partly uncertain continuum robots. The new techniques proposed and methodologies adopted in this paper supported by MATLAB/SIMULINK results represent a significant contribution to the field of design an optimized nonlinear computed torque controller for continuum robots.
\end{abstract}

Index Terms - Gradient Descent Optimization Algorithm, Computed Torque Methodology, Fuzzy Computed Torque Algorithm, Continuum Robot, Fuzzy Logic Methodology

\section{Introduction}

Continuum robots represent a class of robots that have a biologically inspired form characterized by flexible backbones and high degrees-of-freedom structures [1]. The idea of creating "trunk and tentacle" robots, (in recent years termed continuum robots [1]), is not new [2]. Inspired by the bodies of animals such as snakes [3], the arms of octopi [4], and the trunks of elephants [5], [6], researchers have been building prototypes for many years. A key motivation in this research has been to reproduce in robots some of the special qualities of the biological counterparts. This includes the ability to "slither" into tight and congested spaces, and (of particular interest in this work) the ability to grasp and manipulate a wide range of objects, via the use of "whole arm manipulation" i.e. wrapping their bodies around objects, conforming to their shape profiles. Hence, these robots have potential applications in whole arm grasping and manipulation in unstructured environments such as rescue operations. Theoretically, 
the compliant nature of a continuum robot provides infinite degrees of freedom to these devices. However, there is a limitation set by the practical inability to incorporate infinite actuators in the device. Most of these robots are consequently underactuated (in terms of numbers of independent actuators) with respect to their anticipated tasks. In other words they must achieve a wide range of configurations with relatively few control inputs. This is partly due to the desire to keep the body structures (which, unlike in conventional rigid-link manipulators or fingers, are required to directly contact the environment) "clean and soft", but also to exploit the extra control authority available due to the continuum contact conditions with a minimum number of actuators. For example, the Octarm VI continuum manipulator, discussed frequently in this paper, has nine independent actuated degrees-of-freedom with only three sections. Continuum manipulators differ fundamentally from rigid-link and hyper-redundant robots by having an unconventional structure that lacks links and joints. Hence, standard techniques like the Denavit-Hartenberg (D-H) algorith m cannot be directly applied for developing continuum arm kinematics. Moreover, the design of each continuum arm varies with respect to the flexible backbone present in the system, the positioning, type and number of actuators. The constraints imposed by these factors make the set of reachable configurations and nature of movements unique to every continuum robot. This makes it difficult to formulate generalized kinematic or dynamic models for continuum robot hardware. Chirikjian and Burdick were the first to introduce a method for modeling the kinematics of a continuum structure by representing the curve-shaping function using modal functions [6]. Mochiyama used the Serret- Frenet formu lae to develop kinematics of hyper-degrees of freedom continuum manipulators [5]. For details on the previously developed and more manipulator-specific kinematics of the Rice/Clemson "Elephant trunk" man ipulator, see [1], [2], [5]. For the Air Octor and Octarm continuum robots, more general forward and inverse kinematics have been developed by incorporating the transformations of each section of the manipulator (using D-H parameters of an equivalent virtual rigid link robot) and expressing those in terms of the continuum manipulator section parameters [4]. The net result of the work in [6], [3]-[5] is the establishment of a general set of kinematic algorith ms for continuum robots. Thus, the kinematics (i.e. geometry based modeling) of a quite general set of prototypes of continuum manipulators has been developed and basic control strategies now exist based on these. The development of analytical models to analyze continuum arm dynamics (i.e. physicsbased models involving forces in addition to geometry) is an active, ongoing research topic in this field. From a practical perspective, the modeling approaches currently available in the literature prove to be very complicated and a dynamic model which could be conveniently implemented in an actual device's realtime controller has not been developed yet. The absence of a computationally tractable dynamic model for these robots also prevents the study of interaction of external forces and the impact of collisions on these continuum structures. This impedes the study and ultimate usage of continuum robots in various practical applications like grasping and manipulation, where impulsive dynamics [1], [4] are important factors. Although continuum robotics is an interesting subclass of robotics with promising applications for the future, from the current state of the literature, this field is still in its stages of inception.

Controller is a device which can sense information from linear or nonlinear system (e.g., continuum robot) to improve the systems performance [7-9]. The main targets in designing control systems are stability, good disturbance rejection, and small tracking error[7-12]. Several continuum robot are controlled by linear methodologies (e.g., Proportional-Derivative (PD) controller, Proportional- Integral (PI) controller or Proportional- Integral-Derivative (PID) controller), but when robot works with various payloads and have uncertainty in dynamic models this technique has limitations. In some applications continuum robot are used in an unknown and unstructured environment, therefore strong mathematical tools used in new control methodologies to design nonlinear robust controller with an acceptable performance (e.g., minimum error, good trajectory, disturbance rejection) [8-10].

Computed torque controller (CTC) is a powerful nonlinear controller which it widely used in control of robot manipulator. It is based on feedback linearization and computes the required arm torques using the nonlinear feedback control law. This controller works very well when all dynamic and physical parameters are known but when the robot manipulator has variation in dynamic parameters, in this situation the controller has no acceptable performance[7-14]. In practice, most of physical systems (e.g., robot manipulators) parameters are unknown or time variant, therefore, computed torque like controller used to compensate dynamic equation of robot manipulator[1, 6]. Research on computed torque controller is significantly growing on robot manipulator application which has been reported in [1, 6, 15-20]. Vivas and Mosquera [19]have proposed a predictive functional controller and compare to computed torque controller for tracking response in uncertain environment. However both controllers have been used in feedback linearization, but predictive strategy gives better result as a performance. A computed torque control with non parametric regression models have been presented for a robot arm[16]. This controller also has been problem in uncertain dynamic models. Based on [7- 11, 20-44]and [12-20] computed torque controller is a significant nonlinear controller to certain systems which it is based on feedback linearization and computes the required arm torques using the nonlinear feedback control law. When all dynamic and physical parameters are known, computed torque controller works fantastically; practically a large 
amount of systems have uncertainties, therefore sliding mode controller is one of the best case to solve this challenge.

Gradient descent is a first-order optimization algorithm. Gradient descent works in spaces of any number of dimensions, even in infinite-dimensional ones. In the latter case the search space is typically a function space, and one calculates the Gâteaux derivative of the functional to be minimized to determine the descent direction. The gradient descent can take much iteration to compute a local minimum with a required accuracy, if the curvature in different directions is very different for the given function. To improve the output performance as well as resolve the PD gain updating factor this method is used. The PD gain updating factor of this controller is adjusted off line depending on the iterations.

This paper is organized as follows; section 2, is served as an introduction to the computed torque controller formulation algorith $m$ and its application to control of continuum robot and dynamic of continuum robot. Part 3, introduces and describes the methodology (gradient descent optimal computed torque controller) algorithm. Section 4 is presented the simulation results and discussion and the final section is describing the conclusion.

\section{Theory}

\section{A. Dynamic Formulation of Continuum Robot}

The Continuum section analytical model developed here consists of three modules stacked together in series. In general, the model will be a more precise replication of the behavior of a continuum arm with a greater of modules included in series. However, we will show that three modules effectively represent the dynamic behavior of the hardware, so more complex models are not motivated. Thus, the constant curvature bend exhibited by the section is incorporated inherently within the model. The mass of the arm is modeled as being concentrated at three points whose co-ordinates referenced with respect to (see Figure 1);

Where;

$l$ - Length of the rigid rod connecting the two struts, constant throughout the structure

$k_{1, i}, i=1,2,3$ - Spring constant of actuator 1 at module $i$

$k_{2, i}, i=1,2,3$ - Spring constant of actuator 2 at module $i$

$C_{1, i}, i=1,2,3$ - Damping coefficient of actuator 1 at module $i$

$C_{2, i}, i=1,2,3$ - Damping coefficient of actuator 2 at module $i$ $m_{i}, i=1,2,3$ - Mass in each module

$I_{i}, i=1,2,3$ - Moment of inertia of the rigid rod in each module.

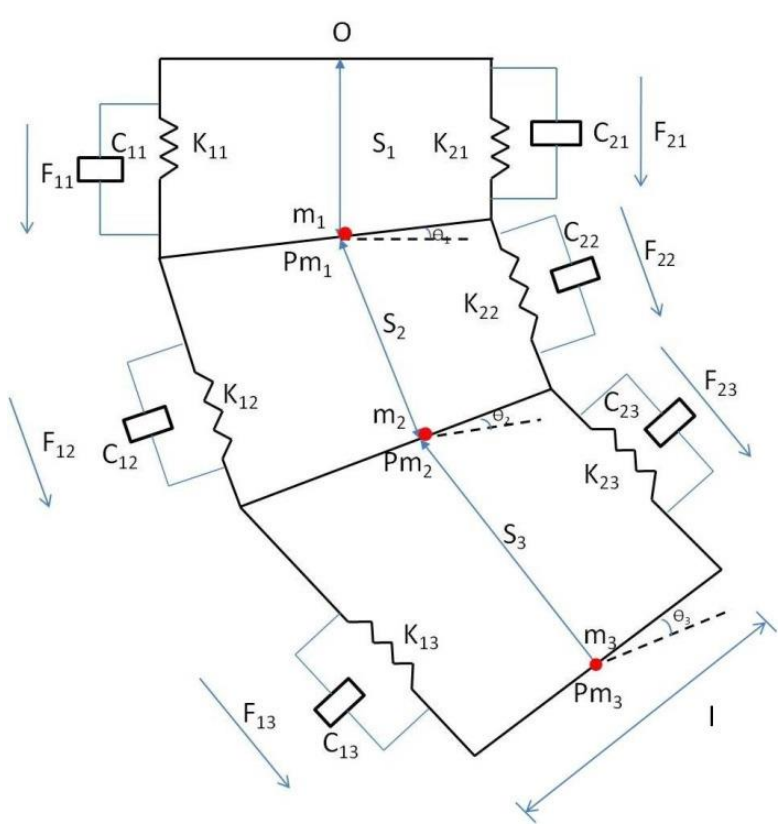

Fig. 1: Assumed structure for analytical model of a section of a continuum arm

A global inertial frame $(\mathrm{N})$ located at the base of the arm are given below

$$
\begin{aligned}
&{ }_{m 1}^{N} P=S_{1} \cdot \widehat{n_{3}} \\
&{ }_{m 2}^{N} P=S_{2} \cdot \sin \theta_{1} \widehat{n_{1}}+\left(S_{1}+S_{2} \cos \theta_{1}\right) \cdot \widehat{n_{3}} \\
&{ }_{m 3}^{N} P=\left(S_{2} \cdot \sin \theta_{1}\right.\left.+S_{3} \cdot \sin \left(\theta_{1}+\theta_{2}\right)\right) \widehat{n_{1}} \\
&+\left(S_{1}\right. \\
&+S_{2} \cos \theta_{1} \\
&\left.\left.+S_{3} \cdot \cos \left(\theta_{1}+\theta_{2}\right)\right)\right) \cdot \widehat{n_{3}}
\end{aligned}
$$

The position vector of each mass is initially defined in a frame local to the module in which it is present. These local frames are located at the base of each module and oriented along the direction of variation of coordinate ' $s$ ' of that module. The positioning of each of these masses is at the centre of mass of the rigid rods connecting the two actuators. Differentiating the position vectors we obtain the linear velocities of the masses. The kinetic energy (T) of the system comprises the sum of linear kinetic energy terms (constructed using the above velocities) and rotational kinetic energy terms due to rotation of the rigid rod connecting the two actuators, and is given below as 


$$
\begin{aligned}
& T=(0.5) m_{1} \dot{s}_{1}{ }^{2}+(0.5) m_{2}\left(\left(\dot{s}_{2} \sin \theta_{1}+\right.\right. \\
& \left.s_{2} \cos \theta_{1} \dot{\theta}_{1}\right)^{2}+\left(\dot{s}_{1}+\dot{s}_{2} \cos \theta_{1}-\right. \\
& \left.\left.s_{2} \sin \theta_{1} \dot{\theta}_{1}\right)^{2}\right)+(0.5) m_{3}\left(\left(\dot{s}_{2} \sin \theta_{1}+\right.\right. \\
& s_{2} \cos \theta_{1} \dot{\theta}_{1}+\dot{s}_{3} \sin \left(\theta_{1}+\theta_{2}\right)+ \\
& s_{3} \cos \left(\theta_{1}+\theta_{2}\right) \dot{\theta}_{1}+s_{3} \cos \left(\theta_{1}+\right. \\
& \left.\left.\theta_{2}\right) \dot{\theta}_{2}\right)^{2}+\left(\dot{s}_{1}+\dot{s}_{2} \cos \theta_{1}-s_{2} \sin \theta_{1} \dot{\theta}_{1}+\right. \\
& \dot{s}_{3} \cos \left(\theta_{1}+\theta_{2}\right)-s_{3} \sin \left(\theta_{1}+\theta_{2}\right) \dot{\theta}_{1}- \\
& \left.\left.s_{3} \sin \left(\theta_{1}+\theta_{2}\right) \dot{\theta}_{2}\right)^{2}\right)+(0.5) I_{1} \dot{\theta}_{1}{ }^{2}+ \\
& (0.5) I_{2}\left(\dot{\theta}_{1}{ }^{2}+\dot{\theta}_{2}{ }^{2}\right)+(0.5) I_{3}\left(\dot{\theta}_{1}{ }^{2}+\right. \\
& \left.\dot{\theta}_{2}{ }^{2}+\dot{\theta}_{3}{ }^{2}\right) .
\end{aligned}
$$

The potential energy $(\mathrm{P})$ of the system comprises the sum of the gravitational potential energy and the spring potential energy. A small angle assumption is made throughout the derivation. This allows us to directly express the displacement of springs and the velocities associated with dampers in terms of system generalized coordinates.

$$
\begin{aligned}
& P=-m_{1} g s_{1}-m_{2} g\left(s_{1}+s_{2} \cos \theta_{1}\right)- \\
& m_{3} g\left(s_{1}+s_{2} \cos \theta_{1}+s_{3} \cos \left(\theta_{1}+\theta_{1}\right)\right)+ \\
& (0.5) k_{11}\left(s_{1}+(1 / 2) \theta_{1}-s_{01}\right)^{2}+ \\
& (0.5) k_{21}\left(s_{1}+(1 / 2) \theta_{1}-s_{01}\right)^{2}+ \\
& (0.5) k_{12}\left(s_{2}+(1 / 2) \theta_{2}-s_{02}\right)^{2}+ \\
& (0.5) k_{22}\left(s_{2}+(1 / 2) \theta_{2}-s_{02}\right)^{2}+ \\
& (0.5) k_{13}\left(s_{3}+(1 / 2) \theta_{3}-s_{03}\right)^{2}+ \\
& (0.5) k_{23}\left(s_{3}+(1 / 2) \theta_{3}-s_{03}\right)^{2}
\end{aligned}
$$

where, $S_{01}, S_{02}, S_{03}$ are the initial values of $S_{1}, S_{2}, S_{3}$ respectively.

Due to viscous damping in the system, Rayliegh's dissipation function [6] is used to give damping energy

$$
\begin{aligned}
& D=(0.5) c_{11}\left(\dot{s}_{1}+(1 / 2) \dot{\theta}_{1}\right)^{2}+ \\
& (0.5) c_{21}\left(\dot{s}_{1}+(1 / 2) \dot{\theta}_{1}\right)^{2}+ \\
& (0.5) c_{12}\left(\dot{s}_{2}+(1 / 2) \dot{\theta}_{2}\right)^{2}+ \\
& (0.5) c_{22}\left(\dot{s}_{2}+(1 / 2) \dot{\theta}_{2}\right)^{2}+ \\
& (0.5) c_{13}\left(\dot{s}_{3}+(1 / 2) \dot{\theta}_{3}\right)^{2}+ \\
& (0.5) c_{23}\left(\dot{s}_{3}+(1 / 2) \dot{\theta}_{3}\right)^{2} .
\end{aligned}
$$

\section{Fcoeff $=$}

The generalized forces in the system corresponding to the generalized co-ordinates are expressed as appropriately weighted comb inations of the input forces.

$$
\begin{aligned}
& Q_{s_{1}}=F_{11}+F_{21}+\left(F_{12}+F_{22}\right) \cos \theta_{1}+ \\
& \left(F_{13}+F_{23}\right) \cos \left(\theta_{1}+\theta_{2}\right) \\
& Q_{s_{2}}=F_{12}+F_{22}+\left(F_{13}+F_{23}\right) \cos \left(\theta_{2}\right) \\
& Q_{s_{3}}=F_{13}+F_{23} \\
& Q_{\theta_{1}}=(1 / 2)\left(F_{11}-F_{21}\right)+ \\
& (1 / 2)\left(F_{12}-F_{22}\right)+(1 / 2)\left(F_{13}-\right. \\
& \left.F_{23}\right)+s_{2} \sin \theta_{2}\left(F_{13}+F_{23}\right) \\
& Q_{\theta_{1}}=(1 / 2)\left(F_{12}-F_{22}\right) \\
& \quad+(1 / 2)\left(F_{13}-F_{23}\right) \\
& Q_{\theta_{1}}=(1 / 2)\left(F_{13}-F_{23}\right)
\end{aligned}
$$

It can be evinced from the force expressions that the total input forces acting on each module can be resolved into an additive component along the direction of extension and a subtractive component that results in a torque. For the first module, there is an additional torque produced by forces in the third module.

The model resulting from the application of Lagrange's equations of motion obtained for this system can be represented in the form

$$
F_{\text {coeff }} \underline{\tau}=D(\underline{q}) \underline{\ddot{q}}+C(\underline{q}) \underline{\dot{q}}+G(\underline{q})
$$

where $\tau$ is a vector of input forces and $\mathrm{q}$ is a vector of generalized co-ordinates. The force coefficient matrix $F_{\text {coeff }}$ transforms the input forces to the generalized forces and torques in the system. The inertia matrix, $D$ is composed of four block matrices. The block matrices that correspond to pure linear accelerations and pure angular accelerations in the system (on the top left and on the bottom right) are symmetric. The matrix $C$ contains coefficients of the first order derivatives of the generalized co-ordinates. Since the system is nonlinear, many elements of $C$ contain first order derivatives of the generalized co-ordinates. The remaining terms in the dynamic equations resulting from gravitational potential energies and spring energies are collected in the matrix $G$. The coefficient matrices of the dynamic equations are given below, 


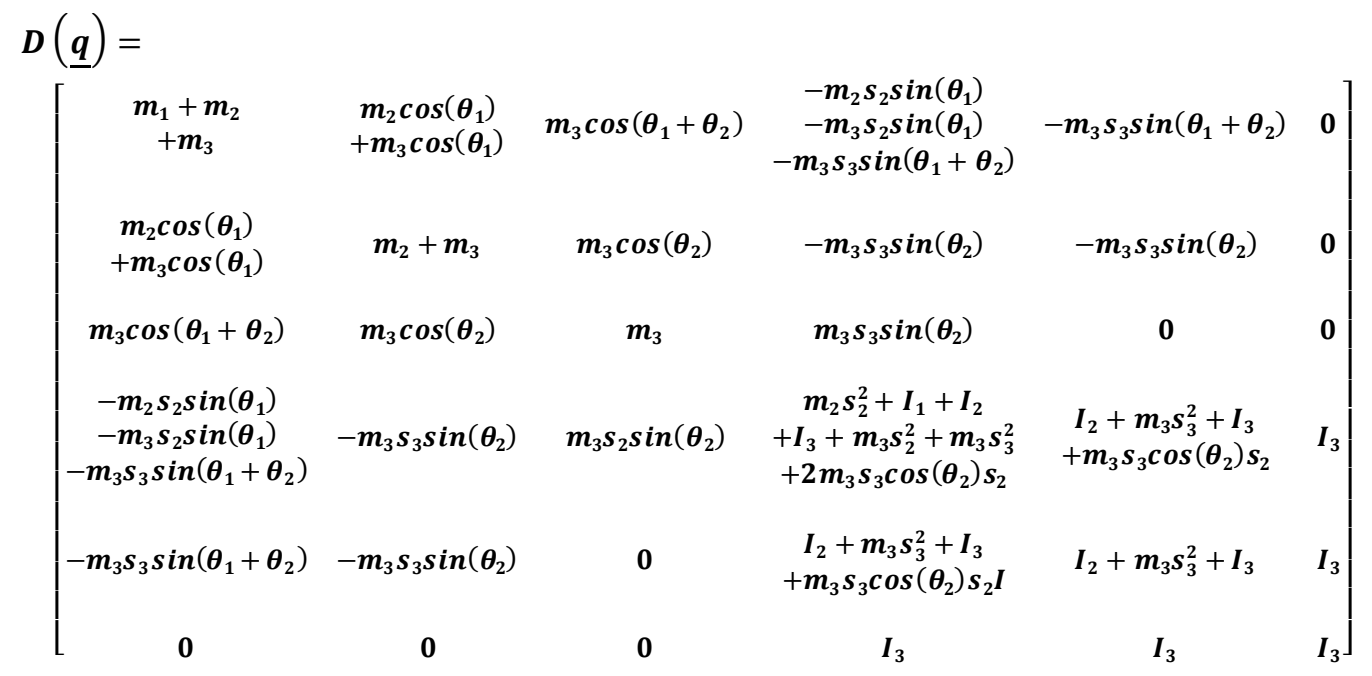

$$
\begin{aligned}
& C(\underline{q})=
\end{aligned}
$$

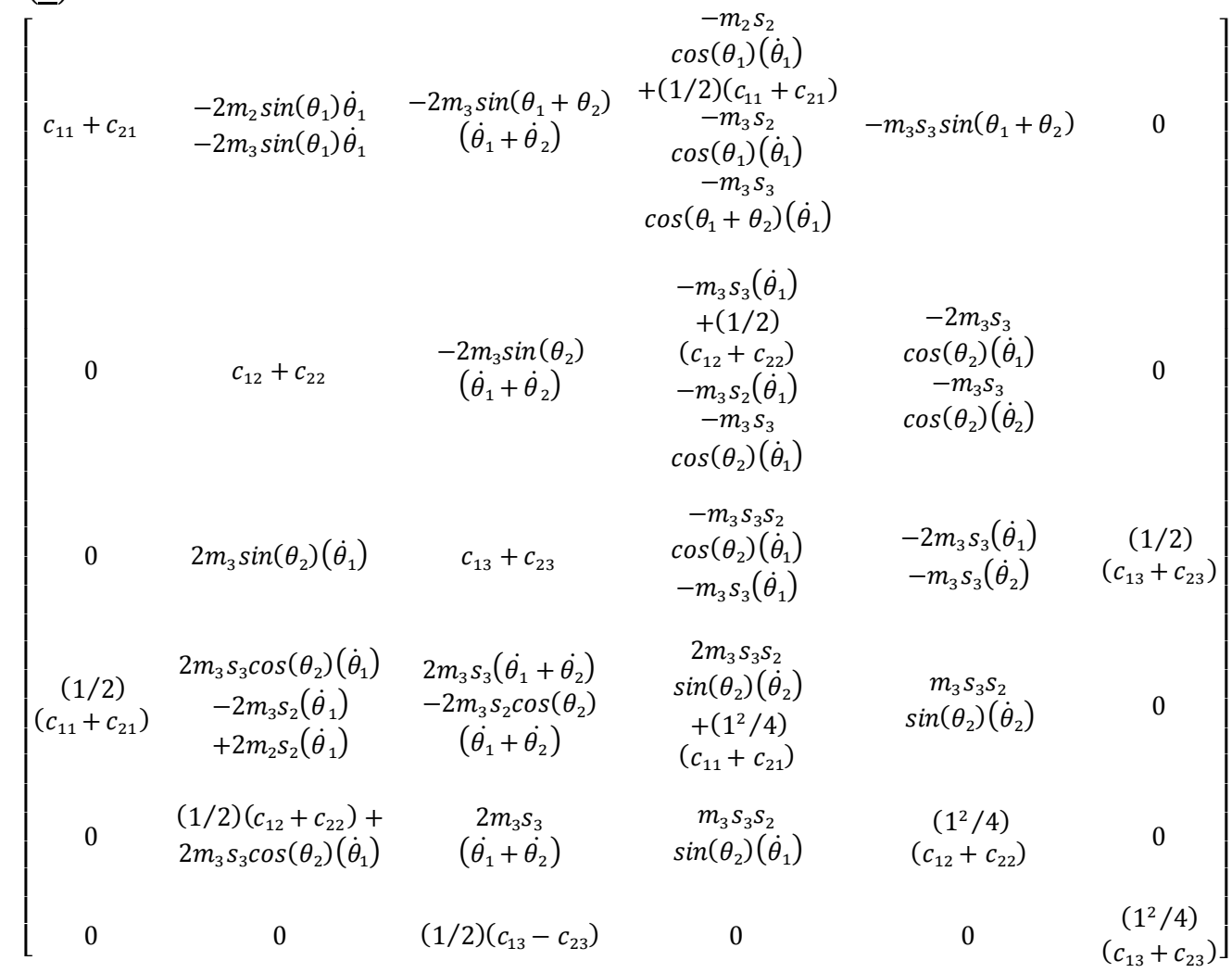

$\boldsymbol{G}(\underline{\boldsymbol{q}})=$

$$
\left[\begin{array}{c}
-m_{1} g-m_{2} g+k_{11}\left(s_{1}+(1 / 2) \theta_{1}-s_{01}\right)+k_{21}\left(s_{1}-(1 / 2) \theta_{1}-s_{01}\right)-m_{3} g \\
-m_{2} g \cos \left(\theta_{1}\right)+k_{12}\left(s_{2}+(1 / 2) \theta_{2}-s_{02}\right)+k_{22}\left(s_{2}-(1 / 2) \theta_{2}-s_{02}\right)-m_{3} g \cos \left(\theta_{1}\right) \\
-m_{3} g \cos \left(\theta_{1}+\theta_{2}\right)+k_{13}\left(s_{3}+(1 / 2) \theta_{3}-s_{03}\right)+k_{23}\left(s_{3}-(1 / 2) \theta_{3}-s_{03}\right) \\
m_{2} s_{2} g \sin \left(\theta_{1}\right)+m_{3} s_{3} g \sin \left(\theta_{1}+\theta_{2}\right)+m_{3} s_{2} g \sin \left(\theta_{1}\right)+k_{11}\left(s_{1}+(1 / 2) \theta_{1}-s_{01}\right)(1 / 2) \\
+k_{21}\left(s_{1}-(1 / 2) \theta_{1}-s_{01}\right)(-1 / 2) \\
m_{3} s_{3} g \sin \left(\theta_{1}+\theta_{2}\right)+k_{12}\left(s_{2}+(1 / 2) \theta_{2}-s_{02}\right)(1 / 2)+k_{22}\left(s_{2}-(1 / 2) \theta_{2}-s_{02}\right)(-1 / 2) \\
k_{13}\left(s_{3}+(1 / 2) \theta_{3}-s_{03}\right)(1 / 2)+k_{23}\left(s_{3}-(1 / 2) \theta_{3}-s_{03}\right)(-1 / 2)
\end{array}\right]
$$




\section{B. Computed Torque Controller}

The central idea of Computed torque controller (CTC) is feedback linearization so, orig inally this algorith $\mathrm{m}$ is called feedback linearization controller. It has assumed that the desired motion trajectory for the manipulator $\boldsymbol{q}_{\boldsymbol{d}}(\boldsymbol{t})$, as determined, by a path planner. Defines the tracking error as [45-66]:

$$
e(t)=q_{d}(t)-q_{a}(t)
$$

Where e(t) is error of the plant, $\boldsymbol{q}_{\boldsymbol{d}}(\boldsymbol{t})$ is desired input variable, that in our system is desired displacement, $\boldsymbol{q}_{\boldsymbol{a}}(\boldsymbol{t})$ is actual displacement. If an alternative linear state-space equation in the form $\dot{\boldsymbol{x}}=\boldsymbol{A} \boldsymbol{x}+\boldsymbol{B} \boldsymbol{U}$ can be defined as

$$
\dot{x}=\left[\begin{array}{ll}
\mathbf{0} & I \\
\mathbf{0} & \mathbf{0}
\end{array}\right] x+\left[\begin{array}{l}
\mathbf{0} \\
\boldsymbol{I}
\end{array}\right] U
$$

With $\boldsymbol{U}=-\boldsymbol{D}^{-\mathbf{1}}(\boldsymbol{q}) \cdot \boldsymbol{N}(\boldsymbol{q}, \dot{\boldsymbol{q}})+\boldsymbol{D}^{-\mathbf{1}}(\boldsymbol{q}) \cdot \boldsymbol{\tau}$ and this is known as the Brunousky canonical form. By equation (18) and (19) the Brunousky canonical form can be written in terms of the state $\boldsymbol{x}=\left[\boldsymbol{e}^{T} \dot{e}^{T}\right]^{T}$ as [11-34]:

$$
\frac{d}{d t}\left[\begin{array}{l}
e \\
\dot{e}
\end{array}\right]=\left[\begin{array}{ll}
0 & I \\
0 & 0
\end{array}\right] \cdot\left[\begin{array}{l}
e \\
\dot{e}
\end{array}\right]+\left[\begin{array}{l}
0 \\
I
\end{array}\right] U
$$

$$
U=\ddot{q}_{d}+D^{-1}(q) .\{N(q \cdot \dot{q})-\tau\}
$$

Then compute the required arm torques using inverse of equation (21), is;

$$
\tau=D(q)\left(\ddot{q_{d}}-U\right)+N(\dot{q}, q)
$$

This is a nonlinear feedback control law that guarantees tracking of desired trajectory. Selecting proportional-plus-derivative (PD) feedback for $U(t)$ results in the PD-computed torque controller [8-10];

$$
\tau=D(q)\left(\ddot{q}_{d}+K_{v} \dot{e}+K_{p} e\right)+N(q, \dot{q})
$$

and the resulting linear error dynamics are

$$
\left(\ddot{q}_{d}+K_{v} \dot{e}+K_{p} e\right)=0
$$

According to the linear system theory, convergence of the tracking error to zero is guaranteed [6]. Where $\boldsymbol{K}_{\boldsymbol{p}}$ and $\boldsymbol{K}_{\boldsymbol{v}}$ are the controller gains. The result schemes is shown in Figure 2, in which two feedback loops, namely, inner loop and outer loop, which an inner loop is a compensate loop and an outer loop is a tracking error loop.

With

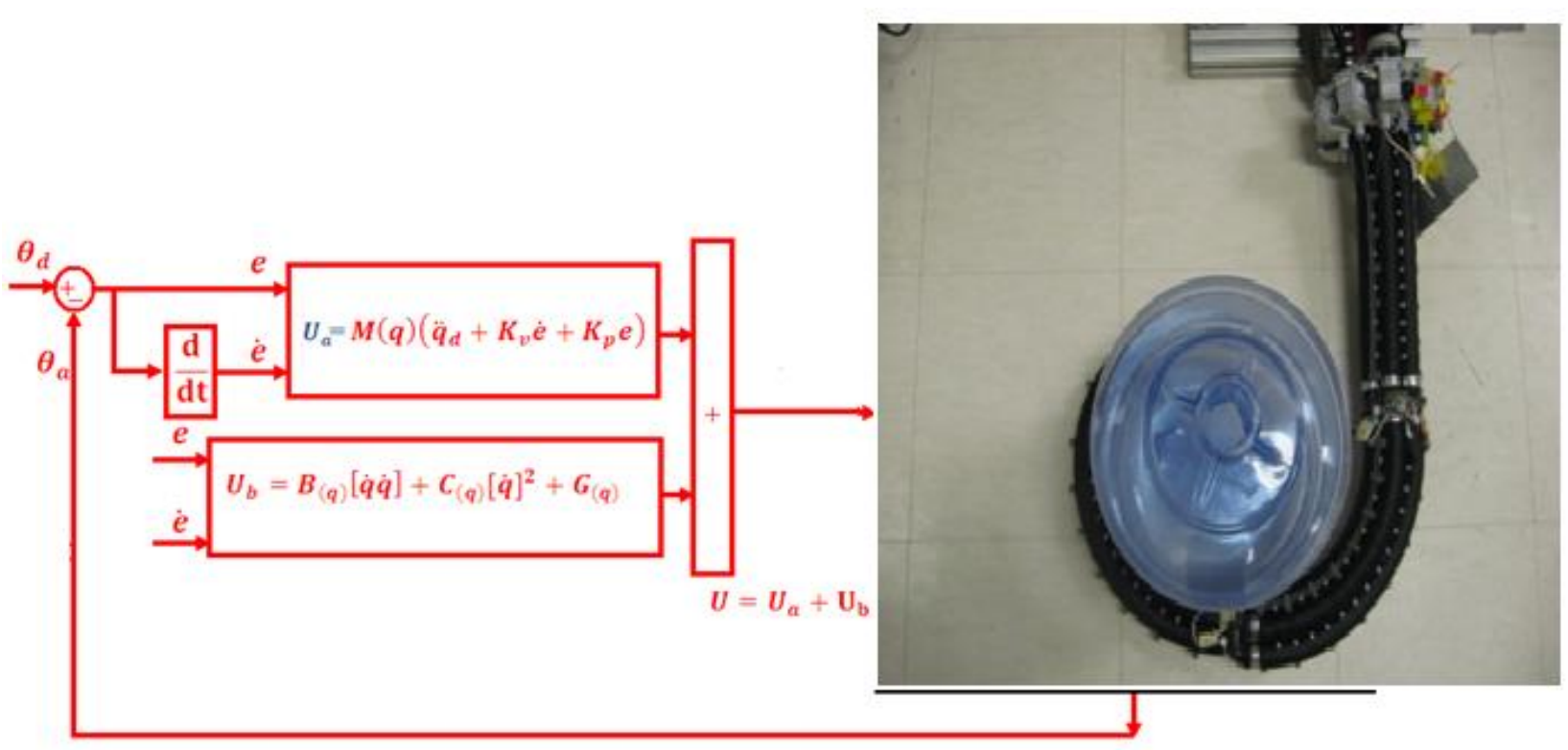

Fig. 2: Block diagram of PD-computed torque controller (PD-CTC)

\section{Fuzzy Inference Engine:}

This section provides a review about foundation of fuzzy logic based on [32- 53]. Supposed that $U$ is the universe of discourse and $x$ is the element of $U$, therefore, a crisp set can be defined as a set which consists of different elements $(x)$ will all or no membership in a set. A fuzzy set is a set that each element has a membership grade, therefore it can be written by the following definition;

$$
A=\left\{x, \mu_{A}(x) \mid x \in X\right\} ; A \in U
$$

Where an element of universe of discourse is $x, \mu_{A}$ is the membership function (MF) of fuzzy set. The 
membership function $\left(\mu_{A}(x)\right)$ of fuzzy set $A$ must have a value between zero and one. If the membership function $\mu_{A}(x)$ value equal to zero or one, this set change to a crisp set but if it has a value between zero and one, it is a fuzzy set. Defining membership function for fuzzy sets has divided into two main groups; namely; numerical and functional method, which in numerical method each number has different degrees of membership function and functional method used standard functions in fuzzy sets. The membership function which is often used in practical applications includes triangular form, trapezoidal form, bell-shaped form, and Gaussian form.

Linguistic variable can open a wide area to use of fuzzy logic theory in many applications (e.g., control and system identification). In a natural artificial language all numbers replaced by words or sentences .

If - then Rule statements are used to formulate the condition statements in fuzzy logic. A single fuzzy If - then rule can be written by

\section{If $x$ is $A$ Then $y$ is $B$}

where $A$ and $B$ are the Linguistic values that can be defined by fuzzy set, the If - part of the part of " $x$ is $A$ " is called the antecedent part and the thenpart of the part of " $y$ is $B$ " is called the Consequent or Conclusion part. The antecedent of a fuzzy if-then rule can have multiple parts, which the following rules shows the multiple antecedent rules:

\section{if $e$ is $N B$ and $\dot{e}$ is $M L$ then $T$ is $L L$}

where $e$ is error, $\dot{e}$ is change of error, $N B$ is Negative Big, $M L$ is Medium Left, $T$ is torque and $L L$ is Large Left. If - then rules have three parts, namely, fuzzify inputs, apply fuzzy operator and apply implication method which in fuzzify inputs the fuzzy statements in the antecedent replaced by the degree of membership, apply fuzzy operator used when the antecedent has multiple parts and replaced by single nu mber between 0 to 1, this part is a degree of support for the fuzzy rule, and apply implication method used in consequent of fuzzy rule to replaced by the degree of membership. The fuzzy inference engine offers a mechanism for transferring the rule base in fuzzy set which it is divided into two most important methods, namely, Mamdani method and Sugeno method. Mamdani method is one of the common fuzzy inference systems and he designed one of the first fuzzy controllers to control of system engine. Mamdani's fuzzy inference system is divided into four major steps: fuzzification, rule evaluation, aggregation of the rule outputs and defuzzification. Michio Sugeno use a singleton as a membership function of the rule consequent part. The following definition shows the Mamdani and Sugeno fuzzy rule base

$$
\begin{array}{ccc}
\text { Mamdani } & \text { F. } R^{1}: \text { if } & x \text { is } A \text { and } \\
y \text { is } B \text { then } \quad z \text { is } C \\
\text { Sugeno F. } R^{1}: \text { if } & x \text { is } A \text { and } \\
y \text { is } B \text { then } & f(x, y) \text { is } C
\end{array}
$$

When $x$ and $y$ have crisp values fuzzification calculates the membership degrees for antecedent part. Rule evaluation focuses on fuzzy operation (AND/OR) in the antecedent of the fuzzy rules. The aggregation is used to calculate the output fuzzy set and several methodologies can be used in fuzzy logic controller aggregation, namely, Max-Min aggregation, Sum-Min aggregation, Max-bounded product, Max-drastic product, Max-bounded sum, Max-algebraic sum and Min-max. Two most common methods that used in fuzzy logic controllers are Max-min aggregation and Sum-min aggregation. Max-min aggregation defined as below

$$
\begin{aligned}
& \mu_{U}\left(x_{k}, y_{k}, U\right)=\mu_{\cup \cup_{i=1}^{r} F R^{i}}\left(x_{k}, y_{k}, U\right) \\
& =\max \left\{\min _{i=1}^{r}\left[\mu_{R}\left(x_{k}, y_{k}\right), \mu_{p_{m}}(U)\right]\right\}
\end{aligned}
$$

The Sum-min aggregation defined as below

$$
\begin{aligned}
& \mu_{U}\left(x_{k}, y_{k}, U\right)=\mu_{\cup \cup_{i=1}^{r} F R}\left(x_{k}, y_{k}, U\right) \\
& =\sum \min _{i=1}^{r}\left[\mu_{R p q}\left(x_{k}, y_{k}\right), \mu_{p_{m}}(U)\right]
\end{aligned}
$$

where $r$ is the number of fuzzy rules activated by $x_{k}$ and $y_{k}$ and also $\mu_{\cup_{i=1}^{r} F R^{i}}\left(x_{k}, y_{k}, U\right)$ is a fuzzy interpretation of $i-t h$ rule. Defuzzification is the last step in the fuzzy inference system which it is used to transform fuzzy set to crisp set. Consequently defuzzification's input is the aggregate output and the defuzzification's output is a crisp number. Centre of gravity method ( $C O G)$ and Centre of area method (COA) are two most common defuzzification methods, which COG method used the following equation to calculate the defuzzification

$$
\operatorname{COG}\left(x_{k}, y_{k}\right)=\frac{\sum_{i} U_{i} \sum_{j=1}^{r} \cdot \mu_{u}\left(x_{k}, y_{k}, U_{i}\right)}{\sum_{i} \sum_{j=1}^{r} \cdot \mu_{u}\left(x_{k}, y_{k}, U_{i}\right)}
$$

and $C O A$ method used the following equation to calculate the defuzzification

$$
\operatorname{COA}\left(x_{k}, y_{k}\right)=\frac{\sum_{i} U_{i}, \mu_{u}\left(x_{k}, y_{k}, U_{i}\right)}{\sum_{i} \mu_{U} \cdot\left(x_{k}, y_{k}, U_{i}\right)}
$$

Where $\operatorname{COG}\left(x_{k}, y_{k}\right)$ and $\operatorname{COA}\left(x_{k}, y_{k}\right)$ illustrates the crisp value of defuzzification output, $U_{i} \in U$ is discrete element of an output of the fuzzy set, $\mu_{U} \cdot\left(x_{k}, y_{k}, U_{i}\right)$ is the fuzzy set membership function, and $r$ is the number of fuzzy rules.

Based on foundation of fuzzy logic methodology; fuzzy $\log$ ic controller has played important rule to design nonlinear controller for nonlinear and uncertain systems [53-66]. However the application area for fuzzy 
control is really wide, the basic form for all command types of controllers consists of;

- Input fuzzification (binary-to-fuzzy[B/F]conversion)

- Fuzzy rule base (knowledge base)

- Inference engine

- Output defuzzification (fuzzy-tobinary $[\mathrm{F} / \mathrm{B}]$ conversion).

\section{Methodol ogy}

\section{Gradient Descent Fuzzy Model-base Computed Torque Optimization Algorithm}

For computed torque controller application the system performances are sensitive to the controller coefficients $\left(\boldsymbol{K}_{\boldsymbol{p}}, \boldsymbol{K}_{\boldsymbol{v}}\right)$. Therefore to have a good response, compute the best value controller coefficients are very important. Gradient descent algorithm is based on improving the input parameters by moving iteratively in the direction of the estimated gradient of the response of interest. One of the major concerns with this type of algorithm is the estimation of the gradient and its statistical properties. Naturally, the heart of gradient\{based algorithms is the technique used to estimate the gradient. Here we present the most common methods used in the simulation optimization literature. Gradient descent is based on the observation that if the multivariable function $\boldsymbol{F}(\boldsymbol{x})$ is defined and differentiable in a neighborhood of a point $\overline{\boldsymbol{a} \text {, then } \boldsymbol{F}(\boldsymbol{x})}$ decreases fastest if one goes from $\boldsymbol{a}$ in the direction of the negative gradient of $\boldsymbol{F}$ at, $\boldsymbol{a}-\boldsymbol{\nabla} \boldsymbol{F}(\boldsymbol{a})$. It follows that, if

$$
b=a-\gamma \nabla F(a)
$$

for $\gamma \rightarrow 0$ a small enough number, then $F(a)<F(b)$. With this observation in mind, one starts with a guess $x_{0}$ for a local minimum of $F$, and considers the sequence $x_{0}, x_{1}, x_{2}, \ldots$. such that

$$
\boldsymbol{X}_{n+1}=\boldsymbol{X}_{\boldsymbol{n}}-\gamma_{n} \nabla F\left(X_{n}\right), \quad n \geq 0
$$

We have

$$
F\left(X_{0}\right) \geq F\left(X_{1}\right) \geq F\left(X_{2}\right), \geq \cdots
$$

So hopefully the sequence $\left(X_{n}\right)$ converges to the desired local minimum. Note that the value of the step size $\gamma$ is allowed to change at every iteration. With certain assumptions on the function $F$ (for example, $F$ convex and $\nabla F$ Lipschitz) and particular choices of $\gamma($ e.g., chosen via a line search that satisfies the Wolfe conditions), convergence to a local minimum can be guaranteed. When the function $F$ is convex, all local minima are also global minima, so in this case gradient descent can converge to the global solution.

\section{Results and Discussion}

Gradient descent optimal algorith m computed torque controller (GDACTC) was tested to Step response trajectory. In this simulation, to control position of continuum robot the first, second, and third joints are moved from home to final position without and with external disturbance. The simulation was implemented in MATLAB/SIMULINK environment. These systems are tested by band limited white noise with a predefined $40 \%$ of relative to the input signal amplitude. This type of noise is used to external disturbance in continuous and hybrid systems and applied to nonlinear dynamic of these controllers.

Gradient descent optimal algorithm computed torque controller Optimization: in GDA CTC; controllers performance are depended on the controller's coefficient gain $\left(K_{p}\right.$ and $\left.K_{v}\right)$. These two coefficients are computed by GDA optimization; Figures 3 and 4.

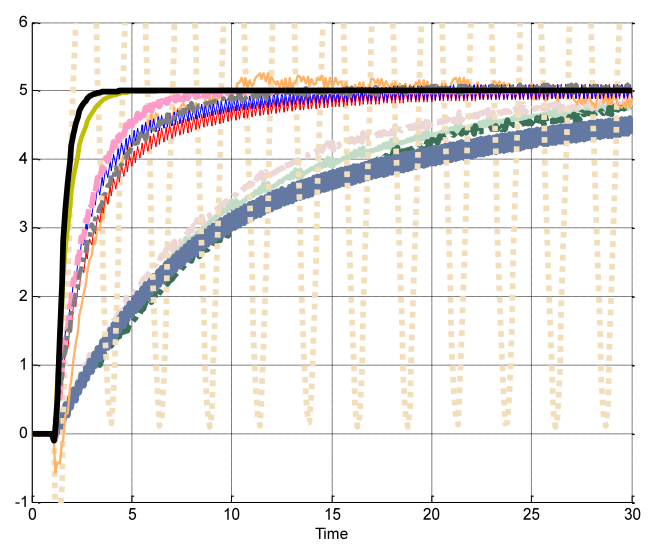

Fig. 3: Trajectory Gradient descent optimization in FMCTC

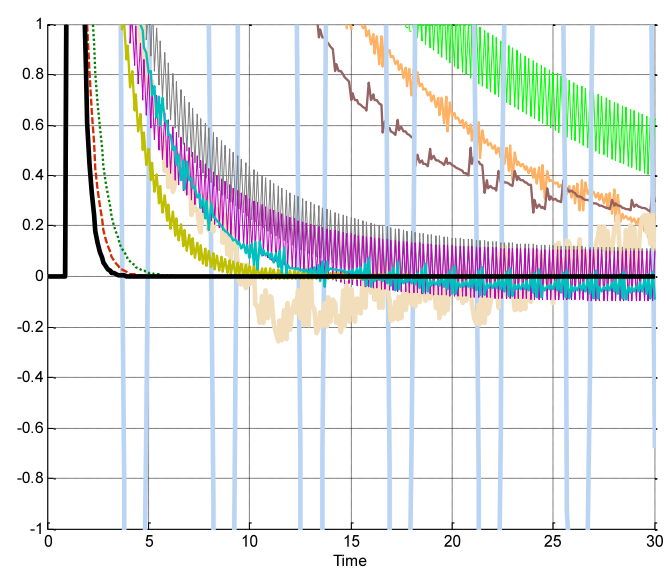

Fig. 4: Error; Gradient descent optimization in FMCTC

Tracking performances: Figure 5 shows tracking performance for GDA-CTC and CTC without disturbance. By trial and error $K_{p}$ and $K_{v}$ coefficients are; $K_{p}=70, K_{v}=15$, and $K_{i}=75 ; \quad$ From the 
simulation for first, second, and third links, it was seen that the different controller gains have the different performance. Tuning parameters of CTC by trial and error and gradient descent optimization for continuum robot are shown in Table 1.

Table 1: Tuning parameters of a step CTC by trial and error

\begin{tabular}{|c|c|c|c|c|}
\hline & 1 & 2 & 3 & 4 \\
\hline$K_{P_{1}}$ & 70 & 50 & 70 & 70 \\
\hline$K_{V_{1}}$ & 24 & 24 & 15 & 24 \\
\hline$K_{I_{1}}$ & 70 & 70 & 75 & 50 \\
\hline$K_{P_{2}}$ & 70 & 50 & 70 & 70 \\
\hline$K_{v_{2}}$ & 24 & 24 & 15 & 24 \\
\hline$K_{I_{2}}$ & 70 & 70 & 75 & 50 \\
\hline$K_{P_{3}}$ & 70 & 50 & 70 & 70 \\
\hline$K_{V_{3}}$ & 24 & 24 & 15 & 24 \\
\hline$K_{I_{3}}$ & 70 & 70 & 75 & 50 \\
\hline RMS error & $2.276 \mathrm{e}-5$ & $3.34 \mathrm{e}-5$ & 0 & $3.7 e-5$ \\
\hline SS error $_{1}$ & $-3.81 e-5$ & $-5.6 e-5$ & 0 & $-6.2 e-5$ \\
\hline SS error $_{2}$ & $-3.81 e-5$ & $-5.6 e-5$ & 0 & $-6.2 e-5$ \\
\hline $\mathrm{SS}$ error $_{3}$ & $-3.81 e-5$ & $-5.6 e-5$ & 0 & $-6.2 e-5$ \\
\hline
\end{tabular}
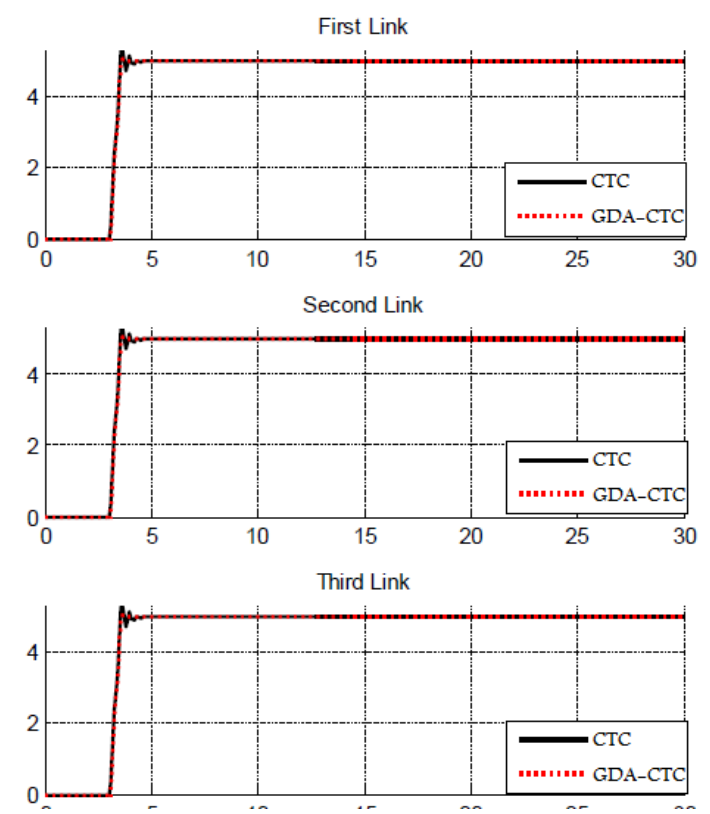

Fig. 5: GDA-FMCTC and CTC for First, second and third link trajectory

By comparing step response trajectory without disturbance in CTC and GDA FMCTC, it is found that the GDACTC's overshoot $\mathbf{( 1 . 3 2 \% )}$ ) is lower than CTC's (6.44\%).

Disturbance rejection: Figure 6 has shown the power disturbance elimination in CTC and GDA CTC. The main target in this controller is disturbance rejection as well as the other responses. A band limited white noise with predefined of $40 \%$ the power of input signal is applied to CTC and GDA CTC. It found fairly fluctuations in trajectory responses. As mentioned earlier, CTC works very well when all parameters are known.
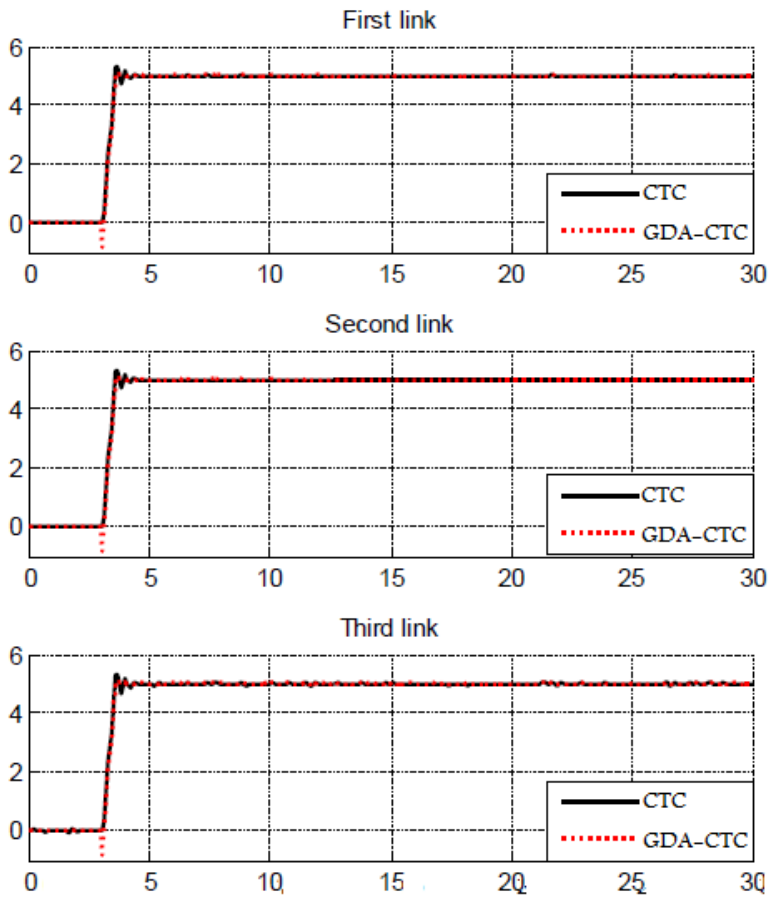

Fig. 6: GDA-FMCTC and CTC for First, second and third link trajectory with disturbance

Among above graph (6) relating to step trajectory following with external disturbance, GDA CTC and CTC have fairly fluctuations. By comparing some control parameters such as overshoot, rise time, steady state and RMS error it computed that the GDACTC's overshoot $\mathbf{( 1 . 8 \% )}$ ) is lower than CTC's $(\mathbf{8 \%})$, although both of them have about the same rise time; GDA CTC $(0.5 \mathrm{sec})$ and CTC (0.41 sec), the Steady State and RMS error in GDA CTC (Steady State error $=\mathbf{- 0 . 0 0 1 9}$ and RMS error $=\mathbf{0 . 0 0 2 5}$ ) is fairly lower than CTC (Steady State error $\cong 0.005$ and $R M S$ error $=0.0042$ ).

Errors in the model: Figure 7 has shown the error disturbance in CTC and GDA CTC. The controllers with no external disturbances have the same error response, but GDA CTC has the better steady state error when the continuum robot has external disturbance. Furthermore the RMS error profile for GDA CTC is sharply dropped compared to the CTC.

The error in GDA CTC and CTC is widely increased among of error graphs (relating to Step response with external disturbance. By comparing the steady state and RMS error it observed that the GDA CTC's steady state and RMS error (Steady State error $=\mathbf{- 0 . 0 0 1 9}$ and RMS error=0.0025) is lower than CTC's (Steady State error $\cong 0.005$ and $\mathbf{R M S}$ error=0.0042 ). When applied disturbance in these controllers it is computed that the steady state and RMS error in CTC increased rapidly approximately $130 \%$ but in GDA CTC it is approximately $22 \%$. 

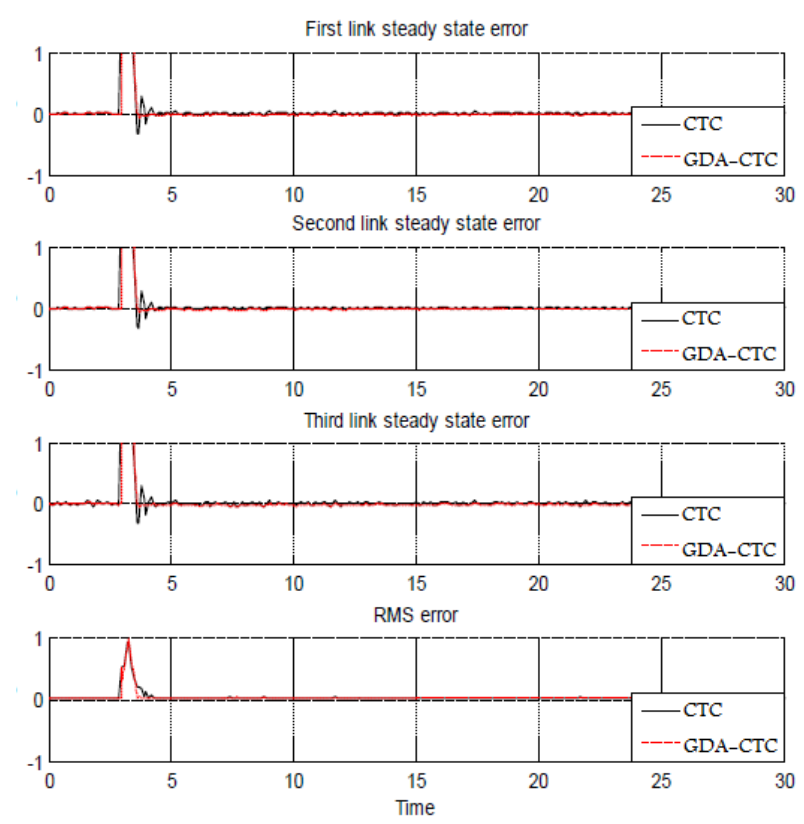

Fig. 7: GDA-FMCTC and CTC for First, second and third link steady state and RMS error with disturbance

\section{Conclusion}

Continuum robot is a nonlinear high degree serial robot. The dynamic parameters of this system are highly nonlinear. To control of this system nonlinear control methodology (computed torque controller) is introduced. Computed torque controller (CTC) is an influential nonlinear controller to certain and partly uncertain systems which it is based on feedback linearization and computes the required arm torques using the nonlinear feedback control law. In most of papers, controller's coefficients calculated by trial and error. In this paper to have the best performance gradient descent optimization is introduce. When all dynamic and physical parameters are known computed torque controller works superbly; practically a large amount of systems have uncertainties and gradient descent optimal fuzzy model base computed torque controller is used. Gradient descent computed torque controller optimization is a mathematical model base method to off-line control of highly nonlinear systems such as continuum robot.

\section{Acknowledgment}

The authors would like to thank the anonymous reviewers for their careful reading of this paper and for their helpful comments. This work was supported by the SSP Research and Development Corporation Program of Iran under grant no. 2012-Persian Gulf-4D.

\section{References}

[1] G. Robinson, and J. Davies, "Continuu m robots - a state of the art,"Proc. IEEE International Conference on Robotics and Automation, Detroit, MI, 1999, vol. 4, pp. 2849-2854.

[2] I.D. Walker, D. Dawson, T. Flash, F. Grasso, R. Hanlon, B. Hochner, W.M. Kier, C. Pagano,C.D. Rahn, Q. Zhang, "Continuum Robot Arms Inspired by Cephalopods, Proceedings SPIE Conference on Unmanned Ground Vehicle Technology VII, Orlando, FL, pp 303-314, 2005.

[3] K. Suzumori, S. Iikura, and H. Tanaka, "Development of Flexible Microactuator and it's Applications to Robotic Mechanisms", Proceedings IEEE International Conference on Robotics and Automation, Sacramento, Californ ia, pp. 1622-1627, 1991.

[4] D. Trivedi, C.D. Rahn, W.M. Kier, and I.D. Walker, "Soft Robotics: Biological Inspiration, State of the Art, and Future Research", Applied Bionics and Biomechanics, 5(2), pp. 99-117, 2008.

[5] W. McMahan, M. Pritts, V. Chitrakaran, D. Dienno, M. Grissom, B. Jones, M. Csencsits, C.D. Rahn, D. Dawson, and I.D. Walker, "Field Trials and Testing of "OCTARM" Continuum Robots", Proc. IEEE International Conference on Robotics and Automation, pp. 2336-2341, 2006.

[6] W. McMahan, I.D. Walker, “Octopus-Ins pired Grasp Synergies for Continuum Manipulators", Proc. IEEE International Conference on Robotics and Biomimetics, pp. 945- 950, 2009.

[7] Farzin Piltan , N. Sulaiman \& M. H. Marhaban, "Design On-Line Tuneable Gain Artificial Nonlinear Controller" Journal of Advance in Computer Research, 2(2): 75-83, 2011.

[8] Farzin Piltan, A lire za Salehi, A min Jalali, A. Reza Zare, Marzie Zare, Ali Roshanzamir \& Farhad Golshan, "Design Sliding Mode Controller for Robot Manipulator with Artificial Tuneable Gain" Canadian journal of Pure and Applied Science,5(2): 1573-1579, 2011.

[9] Farzin Piltan, Shahnaz Tayebi Haghighi, A.Reza Zare, A min Jalali , Ali Roshanzamir, Marzie Zare \& Farhad Golshan, "Artificial Control of Nonlinear Second Order Systems Based on AFGSMC",Australian Journal of Basic and Applied Science,5(6): 509-522, 2011.

[10] Farzin Piltan, A. R. Salehi \& Nasri B Sulaiman,"Design Artificial Robust Control of Second Order System Based on Adaptive Fuzzy Gain Scheduling”, World Applied Science Journal (WASJ), 13 (5): 1085-1092, 2011.

[11] Farzin Piltan, N. Sulaiman, Atefeh Gavahian, Samira Soltani \& Samaneh Roosta, "Design Mathematical Tunable Gain PID-Like Sliding 
Mode Fuzzy Controller with Minimum Rule Base", International Journal of Robotic and Automation, 2 (3): 146-156, 2011

[12] Farzin Piltan , N. Sulaiman, Zahra Tajpaykar, Payman Ferdosali \& Mehdi Rashidi, "Design Artificial Nonlinear Robust Controller Based on CTLC and FSMC with Tunable Gain", International Journal of Robotic and Automation, 2 (3): 205-220, 2011.

[13] Farzin Piltan, N. Sulaiman, M. H. Marhaban, Adel Nowzary \& Mostafa Tohidian, "Design of FPGAbased Sliding Mode Controller for Robot Manipulator", International Journal of Robotic and Automation, 2 (3): 183-204, 2011.

[14] Farzin Piltan, N. Sulaiman, Samaneh Roosta, M.H. Marhaban \& R. Ramli, "Design a New Sliding Mode Adaptive Hybrid Fuzzy Controller”, Journal of Advanced Science \& Engineering Research, 1 (1): 115-123, 2011.

[15] Farzin Piltan, Atefe Gavahian, N. Sulaiman \& M. H. Marhaban, "Novel Sliding Mode Controller for Robot Manipulator using FPGA", Journal of Advanced Science \& Engineering Research, 1 (1): 115-123, 2011.

[16] Farzin Piltan, N. Sulaiman, Payman Ferdosali \& Iraj Assadi Talooki, "Design Model Free Fuzzy Sliding Mode Control: Applied to Internal Combustion Engine", International Journal of Engineering, 5 (4):302-312, 2011.

[17] Farzin Piltan, N. Sulaiman, A. Jalali \& F. Danesh Narouei, "Design of Model Free Adaptive Fuzzy Computed Torque Controller: Applied to Nonlinear Second Order System", International Journal of Robotics and Automation, 2 (4):245-257, 2011

[18]Farzin Piltan, A. Jalali \& N. Sulaiman, "Design of PC-Based Sliding Mode Controller and Normalized Sliding Surface Slope Using PSO Method For Robot Manipulator", International Journal of Robotics and Automation,2 (4): 298-316, 2011.

[19] Farzin Piltan, Amin Jalali, N. Sulaiman, Atefeh Gavahian \& Sobhan Siamak, "Novel Artificial Control of Nonlinear Uncertain System: Design a Novel Modified PSO SISO Lyapunov Based Fuzzy Sliding Mode Algorithm", International Journal of Robotics and Automation, 2 (5): 298-316, 2011.

[20] Farzin Piltan, N. Sulaiman, Iraj Asadi Talooki \& Payman Ferdosali, "Control of IC Engine: Design a Novel MIMO Fuzzy Backstepping Adaptive Based Fuzzy Estimator Variable Structure Control', International Journal of Robotics and Automation, 2 (5):360-380, 2011.

[21] Farzin Piltan, N. Sulaiman, S.Soltani, M. H. Marhaban \& R. Ramli, "An Adaptive Sliding
Surface Slope Adjustment in PD Sliding Mode Fuzzy Control For Robot Manipulator", International Journal of Control and Automation, 4 (3): 65-76, 2011.

[22] Farzin Piltan, N. Sulaiman, Mehdi Rashidi, Zahra Tajpaikar \& Payman Ferdosali, "Design and Implementation of Sliding Mode Algorithm: Applied to Robot Manipulator-A Review", International Journal of Robotics and Automation, 2 (5):265-282, 2011.

[23] Farzin Piltan, N. Sulaiman , Arash Zargari, Mohammad Keshavarz \& Ali Badri, "Design PIDLike Fuzzy Controller with Minimum Rule Base and Mathematical Proposed On-line Tunable Gain: Applied to Robot Manipulator", International Journal of Artificial Intelligence and Expert System, 2 (4):184-195, 2011.

[24] Farzin Piltan, SH. Tayebi HAGHIGHI, N. Sulaiman, Iman Nazari \& Sobhan Siamak, "Artificial Control of PUMA Robot Manipulator: A-Review of Fuzzy Inference Engine and Application to Classical Controller', International Journal of Robotics and Automation, 2 (5):401 -425, 2011.

[25] Samira Soltani \& Farzin Piltan, "Design Artificial Nonlinear Controller Based on Computed Torque like Controller with Tunable Gain", World Applied Science Journal (WASJ), 14 (9): 1306 1312, 2011.

[26] Farzin Piltan, N. Sulaiman \& I.AsadiTalooki, "Evolutionary Design on-line Sliding Fuzzy Gain Scheduling Sliding Mode Algorithm: Applied to Internal Combustion Engine", International Journal of Engineering Science and Technology, 3 (10):7301-7308, 2011.

[27] Farzin Piltan, Nasri B Su laiman, Iraj Asadi Talooki \& Pay man Ferdosali, ”Designing On-Line Tunable Gain Fuzzy Sliding Mode Controller Using Sliding Mode Fuzzy Algorithm: Applied to Internal Combustion Engine" World Applied Science Journal (WASJ), 15 (3): 422-428, 2011.

[28] Farzin Piltan , A. Zare, Nasri B. Sulaiman, M. H. Marhaban \& R. Ramli, "A Model Free Robust Sliding Surface Slope Adjustment in Sliding Mode Control for Robot Manipulator", World Applied Science Journal (WASJ), 12 (12): 2330-2336, 2011.

[29] Farzin Piltan , A. H. Aryanfar, Nasri B. Sulaiman, M. H. Marhaban \& R. Ramli, "Design Adaptive Fuzzy Robust Controllers for Robot Manipulator", World Applied Science Journal (WASJ), 12 (12): 2317-2329, 2011.

[30] Farzin Piltan, N. Sulaiman, Payman Ferdosali, Mehdi Rashidi \& Zahra Tajpeikar, "Adaptive MIMO Fuzzy Compensate Fuzzy Sliding Mode Algorithm: Applied to Second Order Nonlinear 
System", International Journal of Engineering, 5 (5): 380-398, 2011.

[31] Farzin Piltan, N. Sulaiman, Hajar Nasiri, Sadeq Allahdadi \& Mohammad A. Bairami, "Novel Robot Manipulator Adaptive Artificial Control: Design a Novel SISO Adaptive Fuzzy Sliding Algorithm Inverse Dynamic Like Method", International Journal of Engineering, 5 (5): 399418, 2011.

[32] Farzin Piltan, N. Sulaiman, Sadeq Allahdadi, Mohammadali Dialame \& Abbas Zare, "Position Control of Robot Manipulator: Design a Novel SISO Adaptive Sliding Mode Fuzzy PD Fuzzy Sliding Mode Control", International Journal of Artificial Intelligence and Expert System, 2 (5):208-228, 2011.

[33] Farzin Piltan, N. Sulaiman, Amin Jalali \& Koorosh Aslansefat, "Evolutionary Design of Mathematical tunable FPGA Based MIMO Fuzzy Estimator Sliding Mode Based Lyapunov Algorithm: Applied to Robot Manipulator", International Journal of Robotics and Automation, 2 (5):317-343, 2011.

[34] Farzin Piltan, N. Sulaiman, Abbas Zare, Mohammadali Dialame \& Sadeq Allahdadi, "Design Adaptive Fuzzy Inference Sliding Mode Algorithm: Applied to Robot Arm", International Journal of Robotics and Automation,3 (1):283-297, 2011.

[35] Farzin Piltan, N. Sulaiman, Samaneh Roosta, Atefeh Gavahian \& Samira Soltani, "Evolutionary Design of Backstepping Artificial Sliding Mode Based Position Algorithm: Applied to Robot Manipulator", International Journal of Engineering, 5 (5):419-434, 2011.

[36]Farzin Piltan, N. Sulaiman, Amin Jalali, Sobhan Siamak \& Iman Nazari, "Control of Robot Manipulator: Design a Novel Tuning MIMO Fuzzy Backstepping Adaptive Based Fuzzy Estimator Variable Structure Control", International Journal of Control and Automation, 4 (4):91-110, 2011.

[37] Farzin Piltan, N. Sulaiman, Atefeh Gavahian, Samaneh Roosta \& Samira Soltani, "On line Tuning Premise and Consequence FIS: Design Fuzzy Adaptive Fuzzy Sliding Mode Controller Based on Lyaponuv Theory", International Journal of Robotics and Automation, 2 (5):381-400, 2011.

[38] Farzin Piltan, N. Sulaiman, Samira Soltani, Samaneh Roosta \& Atefeh Gavahian, "Artificial Chattering Free on-line Fuzzy Sliding Mode Algorithm for Uncertain System: Applied in Robot Manipulator", International Journal of Engineering, 5 (5):360-379, 2011.

[39] Farzin Piltan, Mohammad A.Bairami, Farid Aghayari \& Sadeq Allahdadi, "Design Adaptive Artificial Inverse Dynamic Controller: Design Sliding Mode Fuzzy Adaptive New Inverse
Dynamic Fuzzy Controller", International Journal of Robotics and Automation, (1):13-26, 2011.

[40] Farzin Piltan, Sadeq Allahdadi, Mohammad A.Bairami \& Hajar Nasiri, "Design Auto Adjust Sliding Surface Slope: Applied to Robot Manipulator", International Journal of Robotics and Automation, 3 (1):27-44, 2011.

[41] Farzin Piltan, Mohammadali Dialame, Abbas Zare \& Ali Badri, "Design Novel Lookup Table Changed Auto Tuning FSMC:Applied to Robot Manipulator", International Journal of Engineering, 6 (1):25-41, 2012.

[42] Farzin Piltan, M. Keshavarz, A. Badri \& A. Zargari, "Design Novel Nonlinear Controller Applied to RobotManipulator: Design New Feedback Linearization Fuzzy Controller with Minimum Rule Base Tuning Method", International Journal of Robotics and Automation, 3 (1):1-12, 2012.

[43] Farzin Piltan, Mohammad A.Bairami, Farid Aghayari \& Sadeq Allahdadi, "Design Adaptive Artificial Inverse Dynamic Controller: Design Sliding Mode Fuzzy Adaptive New Inverse Dynamic Fuzzy Controller", International Journal of Robotics and Automation, (1):13-26, 2012.

[44] Farzin Piltan, Sadeq Allahdadi, Mohammad A.Bairami \& Hajar Nasiri, "Design Auto Adjust Sliding Surface Slope: Applied to Robot Manipulator", International Journal of Robotics and Automation, 3 (1):27-44, 2012.

[45] Farzin Piltan, F. Aghayari, M. Rashidian \& M. Shamsodini, "A New Estimate Sliding Mode Fuzzy Controller for RoboticManipulator", International Journal of Robotics and Automation, 3 (1):45-60, 2012

[46] Farzin Piltan, Iman Nazari, Sobhan Siamak, Payman Ferdosali, "Methodology of FPGA-Based Mathematical error-Based Tuning Sliding Mode Controller', International Journal of Control and Automation, 5(1), 89-118, 2012.

[47] Farzin Piltan, Bamdad Boroomand, Arman Jahed \& Hossein Rezaie, "Methodology of Mathematical Error-Based Tuning Sliding Mode Controller", International Journal of Engineering, 6 (2):96-117, 2012.

[48] Farzin Piltan, S. Emamzadeh, Z. Hivand, F. Shahriyari \& Mina Mirazaei. " PUMA-560 Robot Manipulator Position Sliding Mode Control Methods Using MATLAB/SIMULINK and Their Integration into Graduate/Undergraduate Nonlinear Control, Robotics and MATLAB Courses", International Journal of Robotics and Automation, 3(3):106-150, 2012.

[49] Farzin Piltan, A. Hosainpour, E. Mazlomian, M.Shamsodini, M.H Yarmahmoudi. "Online 
Tuning Chattering Free Sliding Mode Fuzzy Control Design: Lyapunov Approach”, International Journal of Robotics and Automation, 3(3):77-105, 2012.

[50] Farzin Piltan, R. Bayat, F. Aghayari, B. Boroomand. "Design Error-Based Linear ModelFree Evaluation Performance Computed Torque Controller", International Journal of Robotics and Automation, 3(3):151-166, 2012.

[51] Farzin Piltan, J. Meigolinedjad, S. Mehrara, S. Rahmdel. "Evaluation Performance of $2^{\text {nd }}$ Order Nonlinear System: Baseline Control Tunable Gain Sliding Mode Methodology”, International Journal of Robotics and Automation, 3(3): 192-211, 2012.

[52] Farzin Piltan, Mina Mirzaei, Forou zan Shahriari, Iman Nazari, Sara Emamzadeh, "Design Baseline Computed Torque Controller", International Journal of Engineering, 6(3): 129-141， 2012.

[53] Farzin Piltan, Sajad Rahmdel, Saleh Mehrara, Reza Bayat, "Sliding Mode Methodology Vs. Computed Torque Methodology Using MATLAB/SIMULINK and Their Integration into Graduate Nonlinear Control Courses", International Journal of Engineering, 6(3): 142-177, 2012.

[54] Farzin Piltan , M.H. Yarmahmoudi, M. Shamsodini, $\quad$ E.Mazlomian, A.Hosainpour. 'PUMA-560 Robot Manipulator Position Computed Torque Control Methods Using MATLAB/SIMULINK and Their Integration into Graduate Nonlinear Control and MATLAB Courses", International Journal of Robotics and Automation, 3(3): 167-191, 2012.

[55] Farzin Piltan, Hossein Rezaie, Bamdad Boroomand, Arman Jahed. "Design Robust Backstepping on-line Tuning Feedback Linearization Control Applied to IC Engine", International Journal of Advance Science and Technology, 11:40-22, 2012.

[56]Farzin Piltan, S. Siamak, M.A. Bairami and I. Nazari. "Gradient Descent Optimal Chattering Free Sliding Mode Fuzzy Control Design: Lyapunov Approach", International Journal of Advanced Science and Technology, 43: 73-90, 2012.

[57] Farzin Piltan, M.R. Rashidian, M. Shamsodini and S. Allahdadi." Effect of Rule Base on the FuzzyBased Tuning Fuzzy Sliding Mode Controller: Applied to $2^{\text {nd }}$ Order Nonlinear System", International Journal of Advanced Science and Technology, 46:39-70, 2012.

[58] Farzin Piltan, A. Jahed, H. Rezaie and B. Boroo mand. " Methodology of Robust Linear Online High Speed Tuning for Stable Sliding Mode Controller: Applied to Nonlinear System",
International Journal of Control and Automation, 5(3): 217-236, 2012.

[59]Farzin Piltan, R. Bayat, S. Mehara and J. Meigolinedjad. "GDO Artificial IntelligenceBased Switching PID Baseline Feedback Linearization Method: Controlled PUMA Workspace”, International Journal of Information Engineering and Electronic Business, 5: 17-26, 2012.

[60]Farzin Piltan, B. Boroomand, A. Jahed and H. Rezaie. "Performance-Based Adaptive Gradient Descent Optimal Coefficient Fuzzy Sliding Mode Methodology", International Journal of Intelligent Systems and Applications, 11: 40-52 2012.

[61] Farzin Piltan, S. Mehrara, R. Bayat and S. Rahmdel. "Design New Control Methodology of Industrial Robot Manipulator: Sliding Mode Baseline Methodology", International Journal of Hybrid Information Technology, 5(4):41-54, 2012.

[62] AH Aryanfar, MR Khammar, Farzin Piltan, "Design a robust self-tuning fuzzy sliding mode control for second order systems", International Journal of Engineering Science REsearch, 3(4): 711-717, 2012.

[63] Farzin Piltan, Shahnaz Tayebi Haghighi, "Design Gradient Descent Optimal Sliding Mode Control of Continuum Robots", International Journal of Robotics and Automation, 1(4): 175-189, 2012.

[64] Farzin Piltan, NB Sulaiman, "Review of Sliding Mode Control of Robotic Manipulator", World Applied Sciences Journal, 18 (12), 1855-1869, 2012.

[65] Farzin Piltan, M. Akbari, M. Piran , M. Bazregar. "Design Model Free Switching Gain Scheduling Baseline Controller with Application to Automotive Engine", International Journal of Information Technology and Computer Science, 01:65-73, 2013.

[66] Farzin Piltan, M. Piran , M. Bazregar, M. Akbari, "Design High Impact Fuzzy Baseline Variable Structure Methodology to Artificial Adjust Fuel Ratio", International Journal of Intelligent Systems and Applications, 02: 59-70, 2013.

\section{Authors' Profiles}

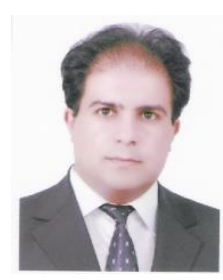

Farzin Piltan was born on 1975, Shiraz, Iran. In 2004 he is jointed the research and development company, SSP Co, Shiraz, Iran. In addition to 7 textbooks, Farzin Piltan is the main author of more than 70 scientific papers in refereed journals. He is editorial board of international journal of control and automation (IJCA), editorial board of International 
Journal of Intelligent System and Applications (IJISA), editorial board of IAES international journal of robotics and automation, editorial board of International Journal of Reconfigurable and Embedded Systems and reviewer of (CSC) international journal of robotics and automation. His main areas of research interests are nonlinear control, artificial control system and applied to FPGA, robotics and artificial nonlinear control and IC engine modelling and control.

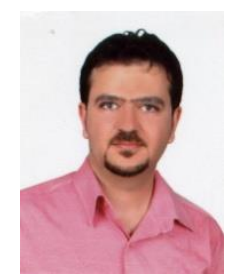

Mehdi Eram is an electrical engineer researcher at research and development company SSP. Co. His research activities deal with the robotics and artificial nonlinear control.

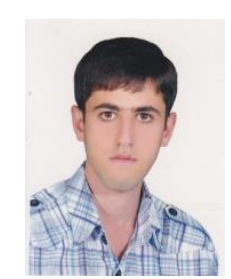

Mohammad Taghavi is a mechanical engineer at research and development company SSP. Co. His main areas are nonlinear control, artificial control systemand robotics.

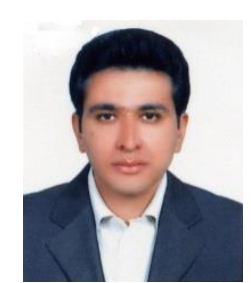

Omid Reza Sadrnia is a communication and electrical engineer researcher at research and development company SSP. Co. He is now pursuing his Master in communication engineering at Shiraz University. His research activities deal with the robotics and artificial nonlinear control.

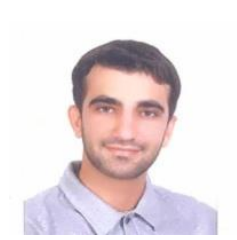

Mahdi Jafari is a communication and electrical engineer researcher at research and development company SSP. Co. He is now pursuing his Master in communication engineering at Shiraz University. His research activities deal with the robotics and artificial nonlinear control.

How to cite this paper: Farzin Piltan, Mehdi Eram, Mohammad Taghavi, Omid Reza Sadrnia, Mahdi Jafari,"Nonlinear Fuzzy Model-base Technique to Compensate Highly Nonlinear Continuum Robot Manipulator", International Journal of Intelligent Systems and Applications(IJISA), vol.5, no.12, pp.135-148, 2013. DOI: 10.5815/ijisa.2013.12.12 